\title{
Comparative Study of Coliform Contamination of Public Boreholes and Pipe Borne Water Systems in Bosso Town, North Central, Nigeria.
}

\author{
*OYEDUM, UM; ADABARA, NU; KUTA, FA \\ Department of Microbiology, School of Life Sciences, Federal University of Technology, Minna. \\ Email of corresponding author: hemdi41@gmail.com
}

\begin{abstract}
This study was carried out to determine the coliform contamination of public boreholes and pipe borne water supplies within Bosso town. Twenty (20) water samples comprising of 10 each of borehole and pipe borne samples were aseptically collected from Bosso Town and analyzed using membrane filtration technique. The results obtained revealed that most $(60.0 \%)$ of the water samples from the borehole sources except the samples from Rafin-Yashi, Maikunkele, Federal University of Technology (F.U.T) Minna, Tudun Fulani, contained coliform counts within $10 \mathrm{cfu} / 100 \mathrm{ml}$ while all $(100.0 \%)$ of the pipe borne water samples had coliform counts above $10 \mathrm{cfu} / 100 \mathrm{ml}$. The organisms isolated included species of Escherichia, Pseudomonas, Streptococcus, Staphylococcus, Salmonella, Shigella, Clostridium, Bacillus, Yersinia and Serratia. E.coli had the highest frequency of occurrence (20\%) followed by Staphylococcus aureus (11.7\%), Salmonella spp (11.7\%), Shigella spp (11.7\%), Clostridium spp (8.3), Streptococcus faecalis (8.3\%), Pseudomonas aeruginosa (6.7\%), Bacillus subtilis (6.7\%), Streptococcus pyrogenes (5\%), Klebsiella spp (3.3\%), Proteus vulgaris (3.3\%), Yersinia spp $(1.7 \%)$ and Serratia spp (1.7\%). This study revealed that pipe borne water and borehole water samples were contaminated in Bosso, with greater contamination observed with pipe borne water. This highlights the need for continuous assessment of the quality of public water supply and intervention measures to prevent outbreak of water-borne diseases in the area.

(C) JASEM
\end{abstract}

http://dx.doi.org/10.4314/jasem.v20i2.2

KEYWORDS: Water; Boreholes; Pipe borne; Coliforms; Water-borne disease

Water is the most valuable and basic natural resources and all lives, especially humans, depend on $70 \%$ water to survive. Water is an essential commodity that is regarded as an important life sustaining drink to humans (Wolfe, 2001). Water fit for human consumption is called drinking or portable water (Oyedum, 2010) and such water can be used for various purposes without any risk of acquiring any water borne disease. Also, when water is distributed to the end users, in a condition in which it is produced with required treatments, the microbial load would be reduced to a safe level (Nwachukwu et al., 2000). Unfortunately, prior to the time water gets to its end users, it is usually prone to various microbial growth, microbiologically-induced chemical changes and contamination with pathogenic microorganisms, which constitute serious threat to public health (Stender et al., 2001). Many people, especially in the developing world depend on untreated surface and ground water sources for their daily water needs, and water from these sources are often faecally contaminated (Omar, 2008).

Most water bodies faecally contaminated clearly indicate that the water body contains other opportunistic organisms that are important to humans, which may cause severe illness and subsequently. Environmental Protection Agency (EPA) (2009) reported that high pathogens in water bodies may result from inadequately treated sewage discharged from various septic tanks, and use of such water by the general populace leads to acquisition of the pathogens through various routes of transmission such as: Oral route, Dermal route and as Aerosol (Hailer et al., 1999; APEC 2010).

The faecal pathogens in water supplies are a very diverse group of organisms such as bacteria (e.g. $E$. Coli 0157: H7, Shigella species, Campylobacter jejuni, Salmonella species and Yersinia species), protozoa (for example, Entamoeba histolytica, Gardia species and Cryptosporidium species) and viruses (e.g. Noroviruses, Enteroviruses, Adenoviruses, Rotaviruses and Hepatitis A and E viruses) (Jorge et al., 2008).Also, some water borne pathogenic disease that may coincide with faecal contamination include ear infections, dysentery, typhoid fever, cholera, encephalitis, giardiasis, gastroenteritis and hepatitis (Hailer et al., 1999). 
Generally water is expected to be a life supporting medium, but studies have shown that water does not only improve the standard of life but can also serve as a carrier of dangerous pathogens (Oyedum, 2010). However, the role of contaminated water in the transmission of disease and the importance of water in public health cannot be overemphasized, based on the fact that it is difficult for the general public to distinguish between safe water and portable water, thereby increasing their vulnerability to illness that normally arises from the consumption of contaminated water. Therefore it is imperative that various public water supplies are evaluated continuously to enable the detection and prevention of disease outbreaks. This study is therefore aimed at evaluating the quality of various public water supplies to Bosso and its envions, where the entire general populace depends on it for their daily activities and survival.

\section{MATERIALS AND METHODS}

Study Areas: The study areas were Bosso Central, Bosso Low-cost, Bosso Estate, Okada Road, Elwaziri, Anguwan Tukura, Tudun Fulani, Rafin Yanshi, Federal University of Technology (FUT) Bosso Campus and Maikunkele all in Bosso Local Government Area of Minna, Niger State, Nigeria. All the taps and boreholes sampled were frequently used by the inhabitants around the area for drinking and other domestic purposes. Most of the pipe borne water sampled was from taps constructed close to buildings with soakaways, while some were constructed close to the refuse dump sites. The boreholes were the conventional types with a depth of 50meters (Adabara et al.,2011). The study was carried out from May to August, 2015.

Collection of Samples: $200 \mathrm{mls}$ each of twenty samples (made up of 10 samples of tap and 10 samples of borehole water) were collected aseptically in sterile sampling bottles and taken to the laboratory immediately for analysis within 48 hours.

Analyses of Samples: The samples were analyzed using membrane filter technique. Prior to filtration, each $200 \mathrm{ml}$ water sample aseptically collected was divided to obtain two sets of $100 \mathrm{ml}$ of the water sample, which were filtered simultaneously using
$0.45 \mu \mathrm{m}$ pore sized membrane filter with $47 \mathrm{~mm}$ diameter. The filter papers for each sample were then aseptically transferred onto two Petri dishes containing absorbent pads soaked previously in membrane lauryl sulphate broth using sterile forceps. These steps were repeated for each sample. The two Petri dishes for each sample were inverted and incubated at $30^{\circ} \mathrm{C}$ for 4 hours. One of the Petri dishes was then transferred to an incubator at $37^{\circ} \mathrm{C}$ for 14 hours to isolate the total coliform, while the second Petri dish was placed in an incubator for $44^{\circ} \mathrm{C}$ for 14 hours for the isolation of faecal coliform respectively. The yellow colonies were counted immediately after the incubation before they decolorized.

Identification of Isolates: Isolates from primary cultures incubated at $\left(37^{\circ} \mathrm{Cand} 44^{\circ} \mathrm{C}\right)$ were aseptically subcultured on to fresh media (MacConkey agar and Nutrient agar) to obtain pure cultures using the streak plate technique. The resultant pure isolates were subcultured into already prepared slant bottles for the purpose of identification and characterization. This was done using cultural characteristics and appropriate biochemical tests such as Coagulase, Catalase, Urease, Indole, Sugar fermentation, Citrate utilization, Mannitol salt and Starch hydrolysis.

\section{RESULT AND DISCUSSION}

Result The result obtained showed that faecal coliform count from the boreholes ranged from 0.0 to $7.0 \mathrm{cfu} / 100 \mathrm{ml}$ while faecal coliform count from the taps ranged from 8.0 to $100.0 \mathrm{cfu} / 100 \mathrm{ml}$.The result also showed that total coliform count from the boreholes ranged from 7.0 to $56.0 \mathrm{cfu} / 100 \mathrm{ml}$ while total coliform count from the taps ranged from 70.0 to $228.0 \mathrm{cfu} / 100 \mathrm{ml}$ (Fig 1). The total coliform counts (TCC) were on the average six times higher than the faecal coliform counts (FCC).

A total of 60 isolates were identified and characterized in descending order of their frequency of occurrence as E.coli, Staphylococcus aureus, Salmonella species, Shigella species, Clostridium species, Streptococcus faecalis, Pseudomonas aeruginosa, Bacillus subtilis, Streptococcus pyogenes, Klebsiella species, Proteus vulgaris, Yersinia species and Serratia species (Table 1). 


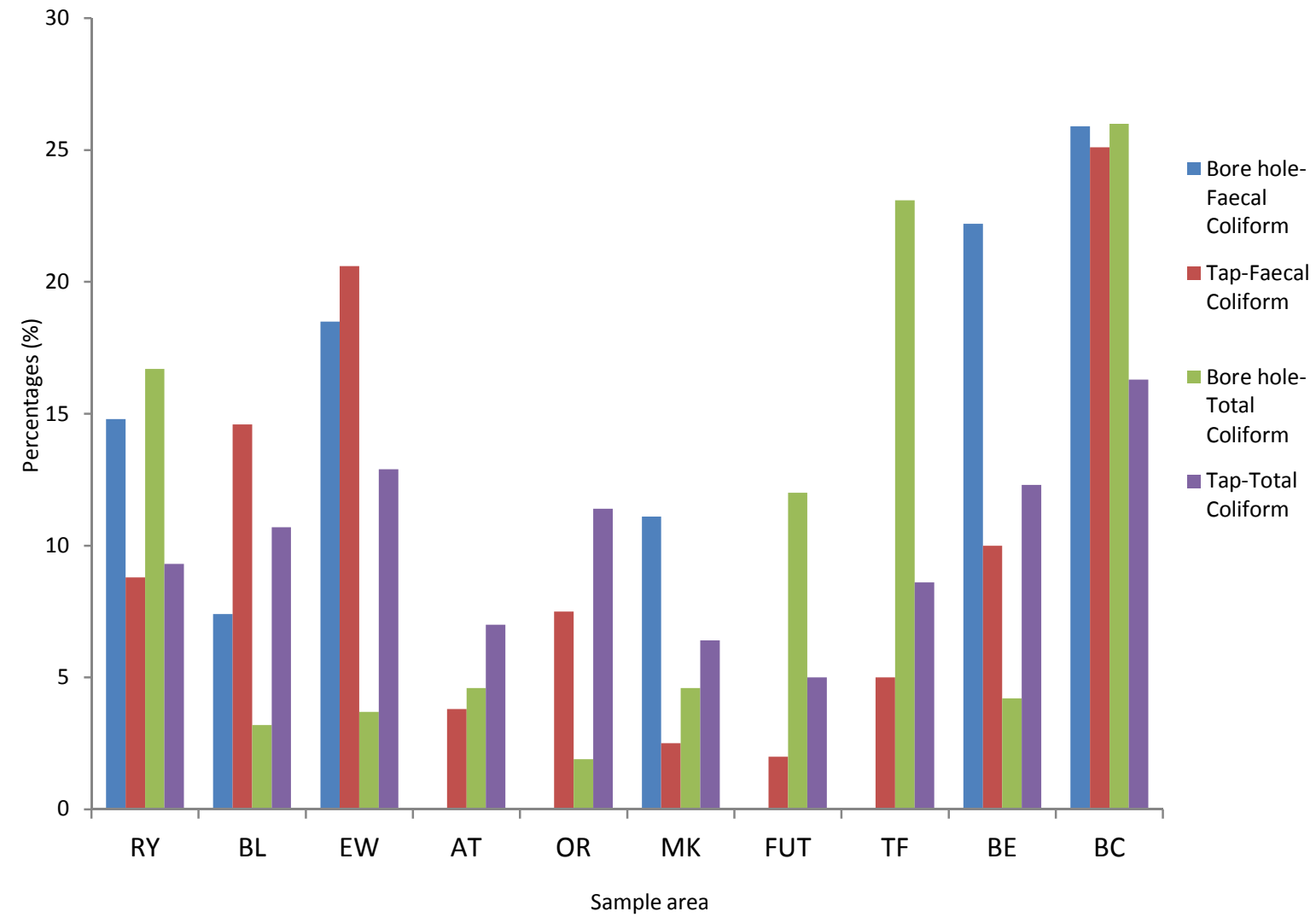

Fig 1: Percentage of Occurrence of the Coliform in Borehole and Tap Water Sample

KEY: RY=Rafin-Yashi; BL=Bosso Lowcost; EW=El-Waziri; AT=Anguwan Tukura; OR= Okada Road; MK=Maikunkele; FUT= Federal University of Technology; TF=Tudun Fulani; BE=Bosso Estate; BC=Bosso Central

Table 1 shows a total of 60 isolates identified and characterized in descending order of their frequency of occurrence as E.coli, Staphylococcus aureus, Salmonella $s p$, Shigella sp, Clostridium sp, Streptococcus faecalis,
Pseudomonas aeruginosa, Bacillus subtilis, Streptococcus pyogenes, Klebsiella sp, Proteus vulgaris, Yersinia sp, and Serratia sp.

Table 1. Frequency of Occurrence of bacterial isolates

\begin{tabular}{lll}
\hline Organisms & Frequency & Percentage frequency $(\%)$ \\
\hline E.coli & 12 & 20.0 \\
Staphylococcus aureus & 7 & 11.7 \\
Salmonella spp & 7 & 11.7 \\
Shigella spp & 7 & 11.7 \\
Clostridium spp & 5 & 8.3 \\
Streptococcus feacalis & 5 & 8.3 \\
Pseudomonas spp & 4 & 6.7 \\
Bacillus substilis & 4 & 6.7 \\
Streptococcus pyrogenes & 3 & 5.0 \\
Klebsiella spp & 2 & 3.3 \\
Proteus vulgaris & 2 & 3.3 \\
Yersinia spp & 1 & 1.7 \\
Serratia spp & 1 & 1.7 \\
\hline Total & 60 & 100 \\
\hline
\end{tabular}


The results shown in Figure 1 revealed that the public water samples analysed within the study area were contaminated. All the boreholes samples except four had coliform counts based on the World Health Organization (WHO) recommended standard, of not more than 10coliform organisms / $100 \mathrm{ml}$ of water for a sample to be acceptable (WHO, 1971). However, all the tap water sampled had coliform counts above 10 coliform organisms $/ 100 \mathrm{ml}$ of water. The borehole water contamination observed in this study may be due to the fact that the boreholes sampled were shallow, and in most cases they served as an environment for supporting the growth of most coliforms that are water dependent. In addition, due to the inadequate fortification of the boreholes and continuous improper usage by the general public, nuts and bolts often loosen, and in the process of repairing them they get exposed to contaminants. This result agrees with the earlier findings from the work of Bala (2006), in Adamawa State of Nigeria, who reported that borehole water compared to tap water is relatively safer because borehole coliform counts usually falls within the WHO recommended standard.

On the other hand, all the water samples from tap had coliform counts above the WHO recommendation standard, this contamination observed in the various taps is an indication that the pipes used in the construction of these taps serve as habitat to various contaminants in the environment due to improper handling during their production and lack of adequate maintenance of these pipes, even prior to their usage in the supply of water enhances the contamination level of the water that passes through them. According to the report of WHO (2003), the level of contamination measured by bacteriological analysis may be a risk factor that could cause outbreak of diseases such as, cholera or typhoid. In addition, the contamination of such tap water is also based on the fact that the source of water channeled through the pipes, is often contaminated with coliforms; and in most cases such pipe borne water lack adequate chlorination treatment (which is the application of chlorine residual of $1 \mathrm{mg} / \mathrm{l}$ or greater for at least 30 minutes) (Ibrahim et $a l ., 2013)$ to eradicate these coliforms before the water is supplied.

The area with the highest percentage of faecal coliform contamination is Bosso Central (Figure 1). This result could be attributed to the fact that various unhygienic life styles such as localized and mechanized farming with human faeces, construction of soakaways, septic tanks and pit latrines and irregular defecation are highly practiced around the locations of these various sources of water in this area. Also farming and construction activities lead to leaching around the borehole sites as well as destruction of the pipelines, and this in turn could lead to penetration of various coliforms into these sources of water supply. This result agrees with the findings of Bala (2006), Mashi (2013) who reported that damage on the pipelines in the environment where they are laid give way for contamination of tap water by sewage which easily seep into the broken pipes, thereby contaminating the water and consequently leading to the cause and spread of waterborne infections, such as typhoid fever, amoebic dysentery, bacillary dysentery, cholera, poliomyelitis and hepatitis as reported by Geldreich (2005), Okoko and Idise (2014).

Organisms isolated from these water samples in this study were species of Escherichia, Pseudomonas, Streptococcus Staphylococcus, Salmonella, Shigella, Clostridium, Bacillus, Yersinia and Serratia. This findings agree with result of Benka-Coker and Olimani (1995) Edema et al.(2006) and Ukpong (2008), which state that these organisms are basically regarded as water resident organisms. E.coli had the highest frequency of occurrence $(20 \%)$ followed in descending order by Staphylococcus aureus (11.7\%), Salmonella spp (11.7\%), Shigella species (11.7\%), Clostridium species (8.3), Streptococcus faecalis (8.3\%), Pseudomonas aeruginosa (6.7\%), Bacillus subtilis (6.7\%), Streptococcus pyrogenes (5\%), Klebsiella species (3.3\%), Proteus vulgaris (3.3\%), Yersinia species (1.7\%) and Serratia species (1.7\%). E. coli with the highest frequency in this study indicates that the water sampled from these various sources were faecally contaminated recently because E.coli is an indicator of recent faecal contamination. The result obtained from this study also agrees with the findings of Bala (2006), who isolated various organisms from the water samples from various areas in Jimeta, Yola, Adamawa State with E.coli having the highest frequency of occurrence.

Conclusion: In conclusion, the indication of contamination in both borehole and tap water is basically due to inadequate attention given to the various water sources and their construction, to enable them serve as portable water systems, which is essential to a human life. It is therefore recommended that environmental health workers should help in carrying out efficient surveillance on the various public water sources on regular basis so as to easily help detect any lapses on the pipelines or boreholes and immediately give suggestions on how to solve the problem to avoid an outbreak of waterborne disease. In addition, the pipelines and boreholes should also be adequately constructed and fortified to avoid damage. Effective and sufficient chlorination treatment should be carried out on various water bodies before they are channeled to various pipelines for public usage. Health workers should also enforce proper hygienic practices, especially around public water supply sources. 


\section{REFERENCES}

Adabara, NU; Mawak, JD; Momohjimoh, A; Bala, JD; Abdulrahaman, AA; Oyedum, UM; Jagaba, A (2011). A relative bacteriological assessment of public borehole and well water in Bosso town, North-Central Nigeria. International Journal of Biomedical and Advance Research. 02(10): 416420.

APEC (2010).Water education: "How does coliform bacteria affect water quality". Retrieved June 10,2010 from http://www.freedrinking water.com.

Bala, JD (2006). "Occurrence of fecal coliform in water sources in Jimeta-Yola”. .Journal of Environmental Science Volume. 10 (2): 064-066.

Benka-Coker, MO; O limani, EL (1995). Investigation of spatial variationsin bacteria distribution in surface water of Ikpoba River. Nigeria Journal of Microbiology. 10: 027-032.

Edema , MO; Omenu, AM; Fapeta, OM (2006). Microbiology and physiological analysis of different sources of drinking water in Abeokuta. Nigeria Journal of Microbiology. 13(1):057-061.

Environmental Protection Agency (2009).Illness related to sewage in water. Accessed February 20,2009. From http://en.wikipedia.org/wiki/waterpollution.

Geldreich, E. (2005). The Bacteriology of water in collier, L; Balows,A; Sussman,M; Wilsons,T.(eds): Microbiology and Microbial infections $9^{\text {th }}$ edition London, Hodder Arnold. Pp 351-363.

Hailer, RW; Witte, JS; Gold, M; Cressey, R; McGee, C; Millikan, RC; Glasser, A; Harawa, N; Ervin, C; Harmon, P; Harper, J; Demand, J; Alamillo, J; Barrette, K; Nides, M; Wang, G (1999).The health effects of swimming in ocean water contaminated by storm drain runoff. Epidermiology.10: 355-363.

Ibrahim, TA; Akenroye, O; Opawale, BO (2013). A Survey of Physicochemical and Bacteriological Quality of Pipe-Borne Water Used for Drinking in Rufus Giwa Polytechnic, Owo Ondo State, Nigeria.Greener Journal of Science, Engineering and Technology Research. 3(6):181-185.
Jorge, W; Santo, D; Nicholas, JA (2008). Faecal pollution of water-Encyclopedia of Earth. Retrieved March 20, 2010.From http://www.ask.com.

Mashi, BH (2013). Comparative bacteriological analysis of drinking water samples in Katsina state. Retrieved March 20,2010.From www.transcampus.org/journals.

Nwachukwu, N; Caldron, RL; Gram, HF (2000). Outbreaks in drinking water systems, 1991-1998. Journal of Environmental Health. 65:016-025.

Okoko, FJ; Idise, OE (2014). Assessment of chemical and bacteriological quality of pipe-borne water from various locations in Delta State University, Abraka, Nigeria. African Journal of Microbiology Research. 8(21):2137-2143.

Omar, KB (2008).Introduction and Literature Review on Water. Retrieved January

25,2010.Fromhttp://ujdigispace.ujac.za:8080/dspace/Str eam/10210/859/2/chapter\%201\%\%20Introductio n\%20and\%20 Literature\%20review.pdf.

Oyedum, MU (2010).Occurrence of faecal coliform contamination of well and borehole water. A project thesis presented to the Department of Microbiology, Federal University of Technology Minna, Niger State, Pp.6.

Stender, A; Broomer, AJ; Olinera, K; Healthier, PO (2001). Detection,identification and enumeration of Escherichia in municipal water. Applied and Environmental Microbiology. 45: 142-147.

Ukpong, JT (2008). Water Quality parameter of domestic water source in Uyo local Government Area, Nigeria. International Journal of Environmental Issues.4:001-002.

Wolfe P. (2000). History of water. World Water.1: 029036.

World Health Organization (WHO) (1971).International Standard for Drinking Water.3rd Edition. WHO. Geneva.

World Health Organization (WHO) (2003). Guidelines for drinking water quality. Pp 81- 87, World Health Organisation, Geneva, Switzerland. 